\title{
Ammoniacal leaching and recovery of copper from alloyed low-grade e-waste
}

\author{
Ewa Rudnik • Maciej Pierzynka • Piotr Handzlik
}

Received: 7 June 2014/ Accepted: 17 November 2014/Published online: 26 November 2014

(C) The Author(s) 2014. This article is published with open access at Springerlink.com

\begin{abstract}
The paper concerns a hydrometallurgical method for selective recovery of copper from low-grade electric and electronic wastes. The following consecutive stages were proposed: smelting of the scraps to produce $\mathrm{Cu}-\mathrm{Zn}-\mathrm{Ag}$ alloy, leaching of the alloy in ammoniacal solution, and selective copper electrowinning. $\mathrm{Cu}-\mathrm{Zn}-\mathrm{Ag}$ alloy was a polymetallic and five-phase system. It was leached in chloride, carbonate, sulfate and thiosulfate solutions. This resulted in the separation of the metals, wherein metallic tin and silver as well as lead salts remained in the slimes, while copper and zinc were transferred to the electrolyte. Copper was selectively recovered from the ammoniacal solutions by the electrolysis, leaving zinc ions in the electrolyte. The best conditions of the alloy treatment were obtained in the ammoniacarbonate system, where the final product was copper of high purity $(99.9 \%)$ at the current efficiency of $60 \%$. Thiosulfate solution was not applicable for the leaching of the copper alloy due to secondary reactions of the formation of copper(I) thiosulfate complexes and precipitation of copper(I) sulfide, both inhibiting dissolution of the metallic material.
\end{abstract}

Keywords Copper - Ammoniacal leaching - Electrolysis . Recovery $\cdot$ E-waste

E. Rudnik $(\bowtie) \cdot$ M. Pierzynka · P. Handzlik Department of Physical Chemistry and Metallurgy of Non-Ferrous Metals, Faculty of Non-Ferrous Metals, AGH University of Science and Technology, Al. Mickiewicza 30, 30-059 Kraków, Poland e-mail: erudnik@agh.edu.pl

\section{Introduction}

Global trend in electric and electronic wastes production goes currently upward and it seems to be continued for a long time $[1,2]$. Despite that e-waste is classified as hazardous, most of it is not recycled and is exported from developed to poor countries in Asia or Africa, where low labor costs, hardly any or no health and environmental restrictions are offered [3]. However, in recent years, some regional regulations have been introduced to force proper management of the stream of this waste by manufacturers, suppliers and importers (e.g., Restriction of Hazardous Substances and Waste Electrical and Electronic Equipment directives in the European Union).

Recovery of metals from secondary sources is a necessary undertaking in the twenty-first century, due to protection of the environment and conservation of natural reserves of the elements. Copper is just one of the many metals present in the electrical and electronic equipment, hence electro-waste is a rich source of the elements. In fact, it often contains higher percentages of valuable metals than native ores. For example, copper and gold abundances in various electronic scraps are up to $20-30 \%$ and $1000 \mathrm{ppm}$ [4], respectively, which corresponds to higher contents of the metals by 20-40 times for copper and up to 1000 times for gold than found usually in the ores. Studies on the waste electronic scraps recycling are concerned mainly on the recovery of precious metals [4-6], while WEEE containing low amounts or no gold, palladium or platinum is classified as a low-value scrap. However, the latter remains still useful for recycling due to the presence of other elements like copper or tin.

Hydrometallurgical recovery of copper from metallic scraps is realized by leaching in acids under oxidative conditions [5, 7] or in ammoniacal solutions [8-10]. 
Alkaline ammonia-ammonium salt solutions show some advantages in the leaching of polymetallic materials [811], since dissolution of copper is specific (autocatalytic):

$$
\begin{aligned}
& \mathrm{Cu}\left(\mathrm{NH}_{3}\right)_{4}^{2+}+\mathrm{Cu} \rightarrow 2 \mathrm{Cu}\left(\mathrm{NH}_{3}\right)_{2}^{+} \\
& 2 \mathrm{Cu}\left(\mathrm{NH}_{3}\right)_{2}^{+}+4 \mathrm{NH}_{4}^{+}+2 \mathrm{OH}^{-}+\frac{1}{2} \mathrm{O}_{2} \\
& \quad \rightarrow 2 \mathrm{Cu}\left(\mathrm{NH}_{3}\right)_{4}^{2+}+3 \mathrm{H}_{2} \mathrm{O}
\end{aligned}
$$

and enhanced separation from co-extracted metals can be obtained. Other elements (e.g., nickel, silver, zinc) occurring in the metallic phase are also transferred into electrolyte as soluble ammine complexes, but the rate of their dissolution is determined by oxygen transport to the metal surface. In addition, ammonium baths give the possibility of iron removal by precipitation of $\mathrm{Fe}$ (III) hydrated oxides in the secondary processes $[12,13]$ :

$$
\mathrm{Fe}+4 \mathrm{NH}_{3}+\mathrm{H}_{2} \mathrm{O}+\frac{1}{2} \mathrm{O}_{2} \rightarrow \mathrm{Fe}\left(\mathrm{NH}_{3}\right)_{4}^{2+}+2 \mathrm{OH}^{-}
$$

$$
\begin{aligned}
& 2 \mathrm{Fe}\left(\mathrm{NH}_{3}\right)_{4}^{2+}+5 \mathrm{H}_{2} \mathrm{O}+\frac{1}{2} \mathrm{O}_{2} \\
& \quad \rightarrow 2 \mathrm{Fe}(\mathrm{OH})_{3}+4 \mathrm{NH}_{4}^{+}+4 \mathrm{NH}_{3} \\
& 2 \mathrm{Fe}(\mathrm{OH})_{3} \rightarrow \mathrm{Fe}_{2} \mathrm{O}_{3} \cdot 3 \mathrm{H}_{2} \mathrm{O}
\end{aligned}
$$

The influence of ammonium salt on the copper recovery from printed circuit boards PCB was reported by Oishi et al. [8]. They found that leaching was more selective for chloride than sulfate system and similar tendency was reported for purification step realized by solvent extraction. Bari et al. [9] also investigated various ammonium salts for copper recovery directly from PCBs and reported the highest leaching efficiency for ammonia-ammonium persulfate solution. At optimum conditions, $90 \% \mathrm{Cu}, 60 \%$ $\mathrm{Zn}$ and $9 \% \mathrm{Ni}$ were dissolved from the waste in $10 \mathrm{~h}$. Copper with a purity of $99.97 \%$ was obtained in the subsequent electrowinning step.

The aim of this work was to investigate the dissolution of an alloy obtained after pyrometallurgical treatment of low-grade e-waste. High-temperature treatment allows removal of all non-metallic elements and organic compounds from the origin material. Based on the previous experience [11], ammoniacal leaching of the multicomponent alloy and further electrolysis were selected for recovery of copper. Recently, Lim et al. [10] presented comparative research on the behavior of some metals $(\mathrm{Cu}, \mathrm{Zn}, \mathrm{Ni}, \mathrm{Pb}, \mathrm{Sn}, \mathrm{Au}, \mathrm{Ag})$ dissolved from pure powders and an alloy obtained from smelting reduction process of mobile phone and printed circuit boards, using sulfate and chloride ammoniacal solutions. In the current paper, the influence of ammonium salts was studied to determine the most suitable bath for the recovery of copper from alloyed electronic scraps. Similar treatment of e-waste was not reported earlier in the literature and usefulness of the novel combined method has been examined.

\section{Materials and methods}

Low-grade electronic scrap from an urban scrap heap was collected and then directly treated pyrometallurgically (without any additives and under natural air contact) for a few hours in an industrial furnace to remove organic compounds (e.g., polymers). Obtained alloy ingot was cut into rectangular samples (approximately $2.5 \mathrm{~cm} \times 2.5 \mathrm{~cm} \times$ $0.7 \mathrm{~cm}$ ). Structure of the alloy was observed under scanning electron microscope (SEM-Hitachi SU-70), while analysis of the chemical composition was performed using energy dispersive spectroscopy (EDS; electron beam accelerating voltage $20 \mathrm{kV}$ ). Analysis was carried out on two crosssections of the ingot cut in the directions perpendicular to each other.

Leaching was carried out in the solutions containing: $0.5 \mathrm{M} \mathrm{NH}_{3}, 1 \mathrm{M}$ ammonium salt (carbonate, chloride, sulfate or thiosulfate) and $50 \mathrm{mM} \mathrm{Cu}^{2+}$ (as suitable cupric salt: basic carbonate, chloride or sulfate). Samples of the alloy were dissolved for $24 \mathrm{~h}$. Solution $\left(400 \mathrm{~cm}^{3}\right)$ was agitated with a magnetic stirrer at a rotation rate of $300 \mathrm{rpm}$. No special aeration of the solution was used. Before and after measurement, all samples were weighed. Slimes produced on the alloy surface were collected, washed, dried at the temperature of $60{ }^{\circ} \mathrm{C}$ for $4 \mathrm{~h}$ and then weighed.

Obtained solutions were used for further recovery of the metal. Individual electrolytes obtained in the leaching stage were diluted to $1 \mathrm{dm}^{3}$ and then portions of $400 \mathrm{~cm}^{3}$ were used for the electrolysis. It was carried out at the current density of $1 \mathrm{~A} / \mathrm{dm}^{2}$ using two platinum electrodes (each $50 \mathrm{~cm}^{2}$, distance between electrodes $8 \mathrm{~cm}$ ) and magnetic stirring $(300 \mathrm{rpm})$. All measurements were performed at ambient temperature.

During leaching and subsequent electrolysis stage, samples $\left(2\right.$ or $\left.2.5 \mathrm{~cm}^{3}\right)$ of the solutions were taken, then diluted with $2 \mathrm{M} \mathrm{H}_{2} \mathrm{SO}_{4}$ and analyzed by atomic absorption spectrometry (AAS Solaar M5, Thermo Elemental) to determine concentrations of $\mathrm{Cu}(\mathrm{I}, \mathrm{II}), \mathrm{Zn}(\mathrm{II}), \mathrm{Pb}(\mathrm{II}), \mathrm{Ni}(\mathrm{II})$, $\mathrm{Fe}(\mathrm{II}, \mathrm{III})$ ions, while mass spectrometry with inductively coupled plasma (ICP-MS ELAN 6100, Perkin Elmer) was used to determine concentrations of $\mathrm{Ag}(\mathrm{I})$ and $\mathrm{Sn}(\mathrm{II}, \mathrm{IV})$ ions. Stationary potential of the leached samples and cathode potential were monitored every 5 min using saturated calomel electrode as a reference. Obtained results were subsequently converted versus standard hydrogen electrode (SHE). 
Solids produced during both processes (i.e., slimes, cathodic deposits) were analyzed using SEM-EDS method (SEM-Hitachi SU-70; electron beam accelerating voltage $15 \mathrm{kV}$ ) or were dissolved in hot $2 \mathrm{M} \mathrm{H}_{2} \mathrm{SO}_{4}$ with $\mathrm{H}_{2} \mathrm{O}_{2}$ addition and then analyzed by means of AAS. X-ray diffractometry (Rigaku diffractometer, $\mathrm{Cu}_{\mathrm{K} \alpha}$ radiation) was used for identification of the phase composition of the slimes and cathodic deposits.

Chemicals of analytical purity were used (Avantor Performance Materials Poland SA).

\section{Results and discussion}

\section{Composition of the alloy}

The alloy obtained from low-grade electronic scraps was a polymetallic and multiphase material with a general composition presented in Table 1 . It contained $72 \% \mathrm{Cu}$, $16 \% \mathrm{Zn}$ and $6 \% \mathrm{Ag}$, comparable amounts of $\mathrm{Fe}$ and $\mathrm{Sn}$ $(\sim 1.5 \%)$ as well as some other metals (each below $1 \%$ ). Figure 1 shows morphology of the cross-section of the ingot. Micrographs were taken using two techniques available for microscopic observations: SE (by means of the secondary electrons detector, Fig. 1a) and BSE (by means of back scattered electrons detector, Fig. 1b). Five phases were found in the alloy: three of them appeared as small inclusions within two-phase brass-based alloy matrix. The latter was able to detect by the analysis in the BSE mode.

Figure 2 shows distribution of the main metals in the alloy. The brass matrix consisted of two phases of various $\mathrm{Sn}$ and $\mathrm{Ag}$ concentrations: phase $\mathrm{I}-3 \% \mathrm{Ag}$ and $0.5 \%$ Sn; phase II-7 \% Ag and $3 \% \mathrm{Sn}$. This segregation was caused by slow migration of the atoms towards lead-rich precipitations during cooling of the smelted material. Phase II gives a net of strips. It contains lead-rich (90\% $\mathrm{Pb}$ in phase III; white areas) and silver-rich $(78 \% \mathrm{Ag}$ in the phase IV; gray areas) inclusions distributed along the centers of the bands. Black inclusions randomly dispersed in the matrix represented iron-rich precipitates $(70 \% \mathrm{Fe}$ in the phase $\mathrm{V}$ ) originated from steel residues in the scrap.

Similar observations of the surface of the second crosssection cut from the ingot in the direction perpendicular to the previous one confirmed that distribution of the phases in the bulk of the alloy was fairly even.

It is worth to note that e-waste is classified generally according to the content of the precious metals, namely $\mathrm{Au}, \mathrm{Pt}$ and Pd. The low-grade scraps used in this study did not contain any from such elements, but obtained alloy was relatively enriched in silver. Despite that such material can be processed further by the traditional pyrometallurgical

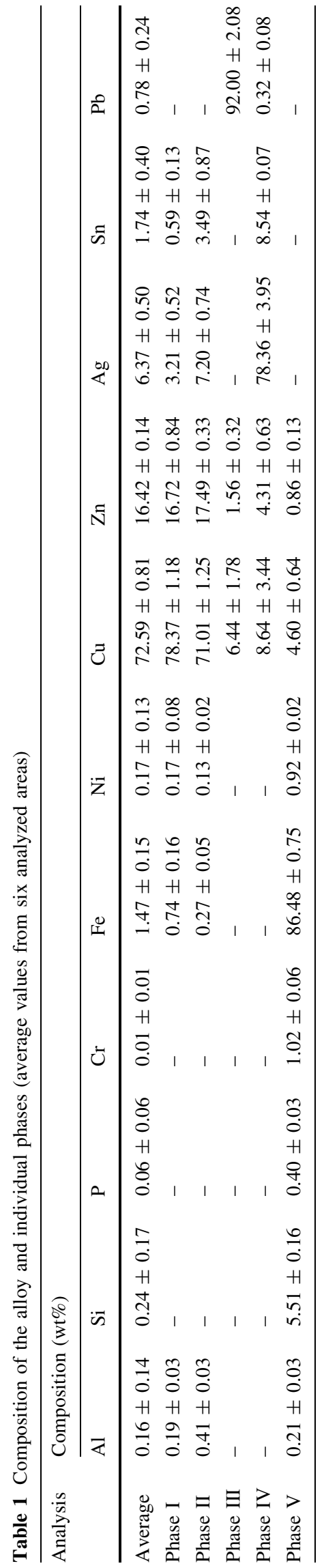



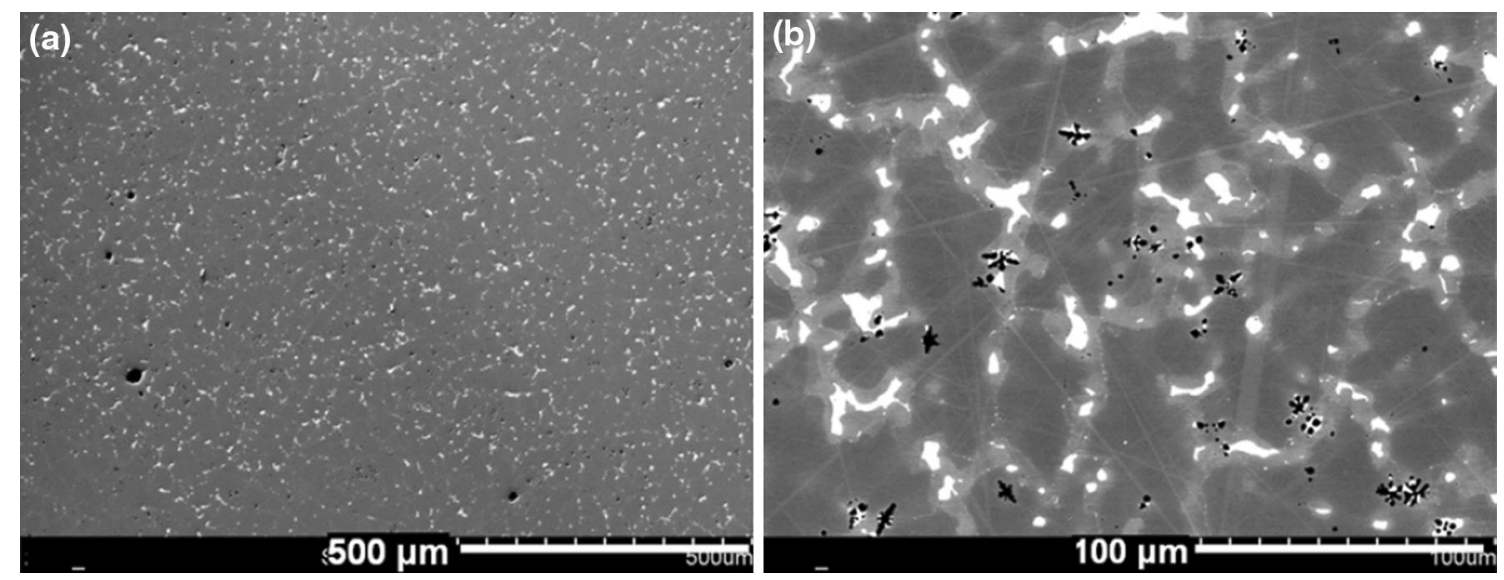

Fig. 1 Morphology of the polished cross-section of the alloy ingot: a SEM mode, b BSE mode
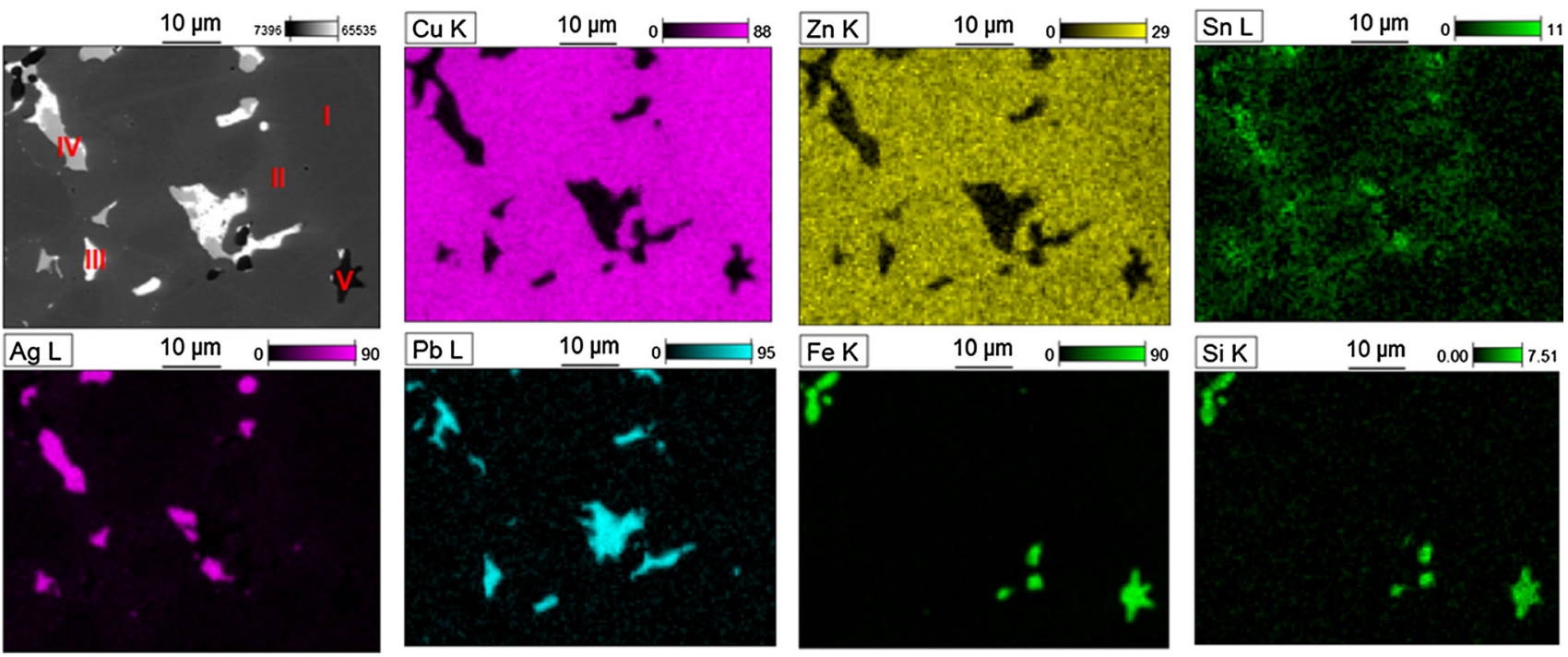

Fig. 2 Distribution of the elements on the cross-section of the alloy ingot

route, a new hydrometallurgical approach for separation of the metals was tested.

\section{Leaching stage}

The alloy was leached in the ammonia solutions containing various ammonium salts, i.e., chloride, carbonate, sulfate or thiosulfate. Cupric ions (approximately $50 \mathrm{mM}$, i.e., $3.1 \mathrm{~g} / \mathrm{dm}^{3}$ ) were introduced also to the baths to force autocatalytic dissolution of copper from the alloy, Eq. (1). This process is useful only for copper-rich alloys, since various phase composition can inhibit spontaneous copper dissolution from the metallic phase [11]. Usually, more concentrated solutions are applied for ammoniacal leaching of the scraps [e.g., $5 \mathrm{M} \mathrm{NH}_{3}$ and $0.5 \mathrm{M} \mathrm{Cu}(\mathrm{II})]$ [8-10], however, in this study, fundamental behavior of the metals during spontaneous dissolution of the alloy was expected to investigate, hence less aggressive baths with natural oxygen content in the solutions were used.

Figure 3 shows changes of the sample potential during the process. For each test, the rising tendency of the potential with the leaching time due to gradual formation of the slime on the alloy surface was observed. Simultaneously, a relationship between the weight loss of the alloy and the value of the corrosion potential was found. The lowest corrosion potential of approx. $-0.37 \mathrm{~V}$ (vs. SHE) was maintained in the thiosulfate bath. It corresponded to the lowest unit mass loss of $0.006 \pm 0.001 \mathrm{~g} /$ $\mathrm{cm}^{2}$ after $24 \mathrm{~h}$. Significantly higher values $(-0.05$ to $0.21 \mathrm{~V})$ were registered in other baths, where active dissolution of the samples was conducted $\left(0.233 \pm 0.002,0.217 \pm 0.004\right.$ and $0.166 \pm 0.006 \mathrm{~g} / \mathrm{cm}^{2}$ for carbonate, chloride and sulfate solution, respectively). 


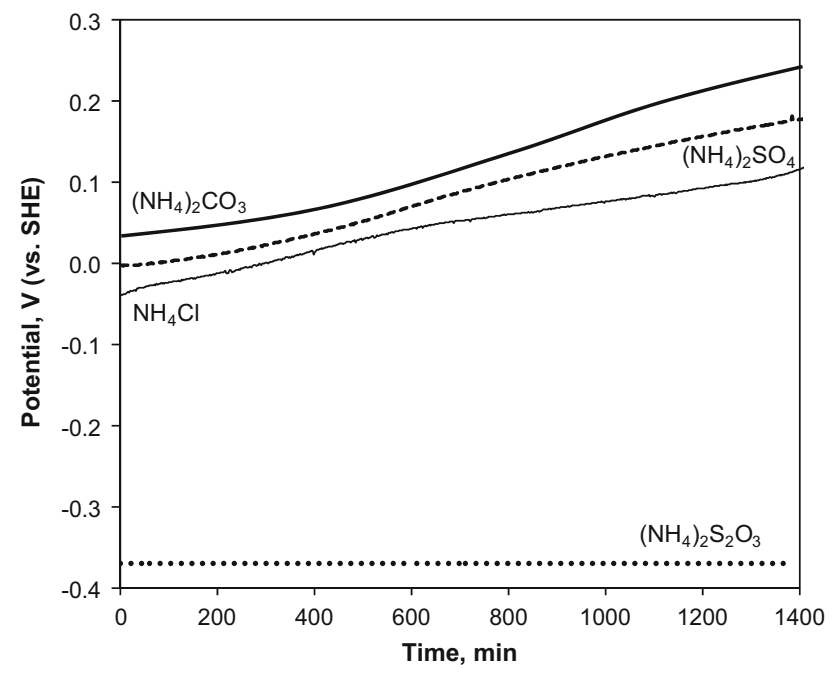

Fig. 3 Changes of the corrosion potential of the alloy within the leaching time
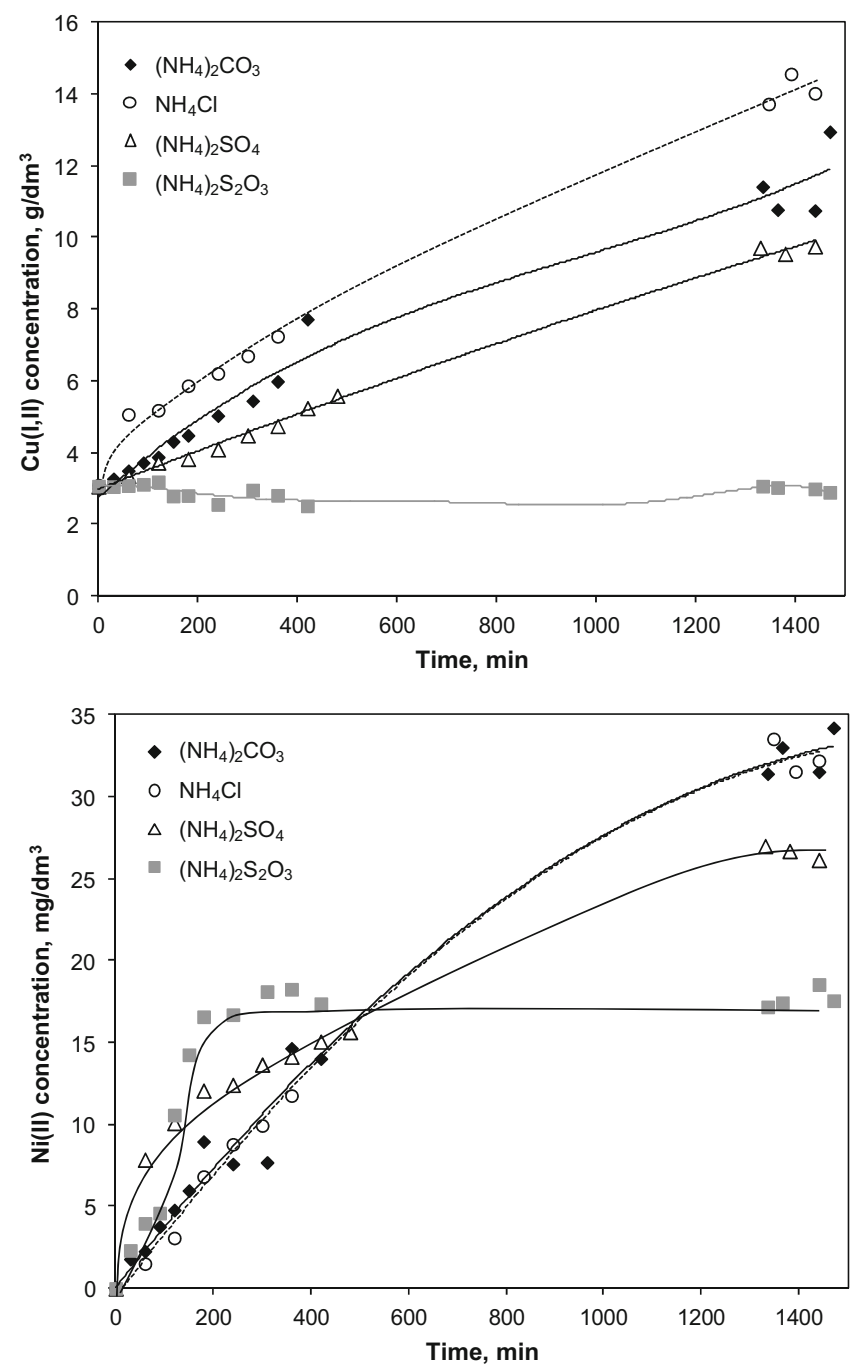

Fig. 4 Changes of metal ions concentrations in the leaching solutions
Low effectiveness of the thiosulfate bath can result from the homogeneous reaction between $\mathrm{Cu}$ (II) and $\mathrm{S}_{2} \mathrm{O}_{3}{ }^{2-}$ ions occurring in the aqueous solution $[12,13]$ :

$$
\begin{aligned}
2 \mathrm{Cu}\left(\mathrm{NH}_{3}\right)_{4}^{2+}+8 \mathrm{~S}_{2} \mathrm{O}_{3}^{2-} \rightarrow & 2 \mathrm{Cu}\left(\mathrm{S}_{2} \mathrm{O}_{3}\right)_{3}^{5-}+4 \mathrm{NH}_{3} \\
& +\mathrm{S}_{4} \mathrm{O}_{6}^{2-}
\end{aligned}
$$

It converts $\mathrm{Cu}(\mathrm{II})$ into $\mathrm{Cu}(\mathrm{I})$ ions, which are inert for the spontaneous dissolution of copper. It is accompanied by the change of the bath from intensely blue to colorless (within $24 \mathrm{~h}$ in this study). Agitation and aeration of the solution return the color for some time [13]:

$$
\begin{gathered}
2 \mathrm{Cu}\left(\mathrm{S}_{2} \mathrm{O}_{3}\right)_{3}^{5-}+8 \mathrm{NH}_{3}+\frac{1}{2} \mathrm{O}_{2}+\mathrm{H}_{2} \mathrm{O} \\
\rightarrow 2 \mathrm{Cu}\left(\mathrm{NH}_{3}\right)_{4}^{2+}+6 \mathrm{~S}_{2} \mathrm{O}_{3}^{2-}+2 \mathrm{OH}^{-}
\end{gathered}
$$

The presence of dissolved air enhances homogeneous reaction (7) and regenerates readily $\mathrm{Cu}(\mathrm{II})$ ions, hence only thiosulfate solution saturated with oxygen may be
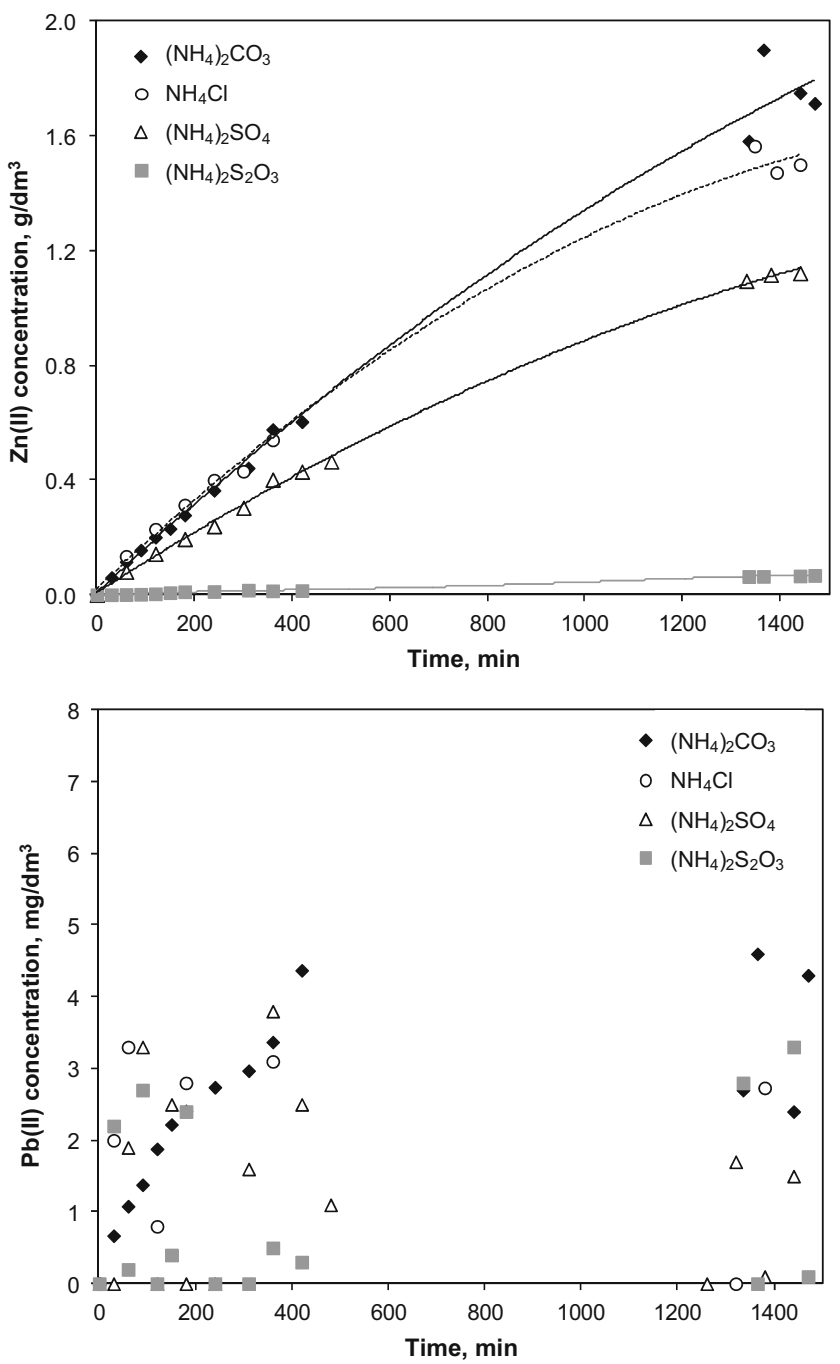


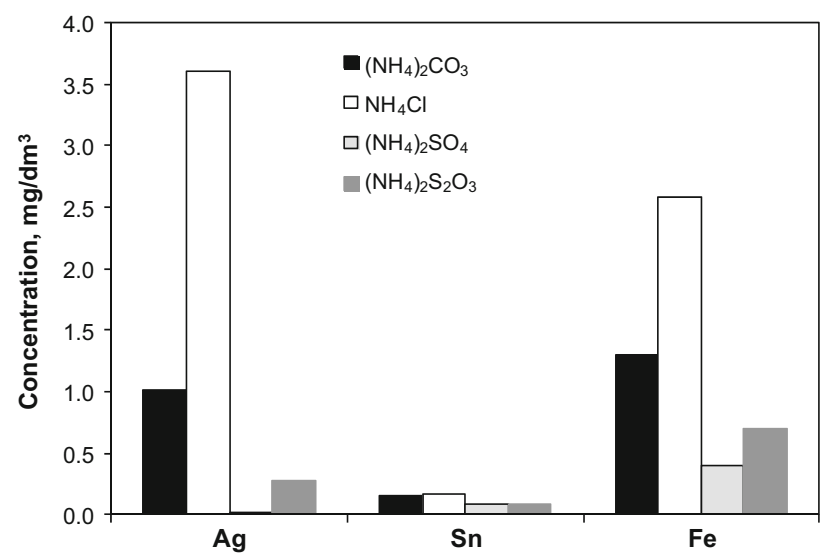

Fig. 5 Final concentrations of metals in the leaching solutions

useful for the autocatalytic metal dissolution. However, agitation of the bath by the magnetic stirrer was not enough to the aeration of the solution during current experiment.

Figure 4 shows changes of $\mathrm{Cu}(\mathrm{I}, \mathrm{II}), \mathrm{Zn}(\mathrm{II}), \mathrm{Ni}(\mathrm{II})$ and $\mathrm{Pb}$ (II) ions concentrations with the leaching time. The highest copper ions increment was obtained in chloride, carbonate and then sulfate solutions, while the smallest changes were found in the thiosulfate bath. The final concentration of copper ions in the latter case was even lower than the initial value. This was due to the precipitation of copper(I) sulfide, thus a significant portion of copper was found then in the slime formed on the alloy surface. Literature data on thiosulfate chemistry show that various equilibria between different sulfur species may attain in the solutions, and $\mathrm{S}_{2} \mathrm{O}_{3}{ }^{2-}$ can decompose in an alkaline environment with the formation of sulfide ion [12]:

$\mathrm{S}_{2} \mathrm{O}_{3}^{2-}+2 \mathrm{OH}^{-} \rightarrow \mathrm{SO}_{4}^{2-}+\mathrm{S}^{2-}+\mathrm{H}_{2} \mathrm{O}$

Therefore, initial dissolution of copper from the alloy is further inhibited by the secondary reaction:

$$
\mathrm{Cu}\left(\mathrm{NH}_{3}\right)_{2}^{+}+\mathrm{S}^{2-} \rightarrow \mathrm{Cu}_{2} \mathrm{~S}+2 \mathrm{NH}_{3}
$$

This is in accordance with thermodynamic data, since the E-pH diagram for $\mathrm{Cu}-\mathrm{NH}_{3}-\mathrm{S}_{2} \mathrm{O}_{3}{ }^{2-}-\mathrm{H}_{2} \mathrm{O}$ system [12] predicts direct formation of $\mathrm{Cu}_{2} \mathrm{~S}$ on the copper surface.

It is worth to note that spontaneous precipitation of $\mathrm{Cu}_{2} \mathrm{~S}$ was also observed in the origin ammoniacal thiosulfate solution during long storage of the electrolyte. It seems to be related to the reduction of cupric ammine complex by $\mathrm{S}_{2} \mathrm{O}_{3}{ }^{2-}$ ions $[14,15]$ :
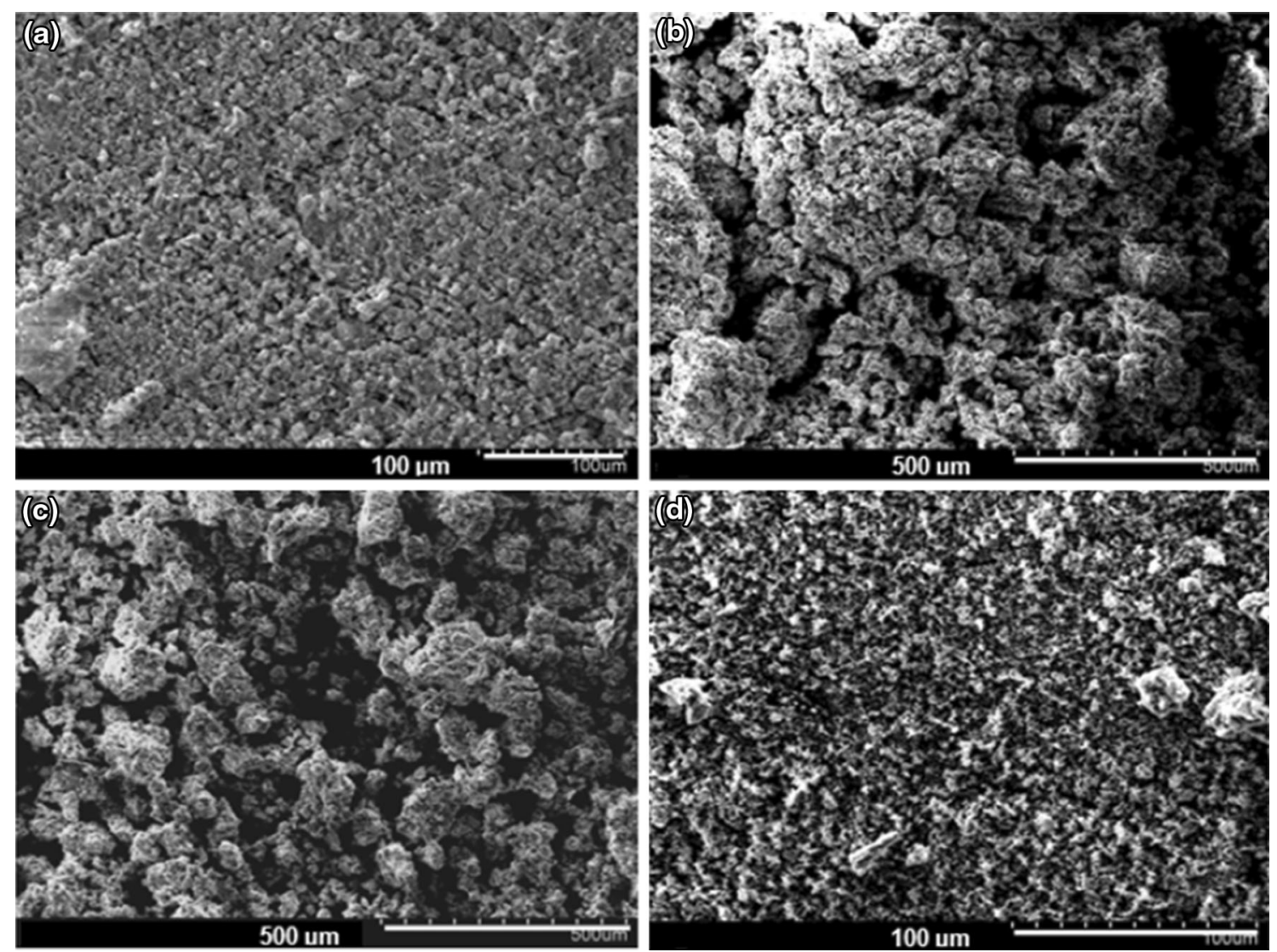

Fig. 6 Morphology of the slimes produced in the ammoniacal baths: a chloride, $\mathbf{b}$ carbonate, $\mathbf{c}$ sulfate, and $\mathbf{d}$ thiosulfate 
Table 2 Average composition of the slimes (EDS-SEM analysis)

\begin{tabular}{|c|c|c|c|c|}
\hline \multirow[t]{2}{*}{ Bath element } & \multicolumn{4}{|c|}{ Composition (wt\%) } \\
\hline & $\left(\mathrm{NH}_{4}\right)_{2} \mathrm{SO}_{4}$ & $\left(\mathrm{NH}_{4}\right)_{2} \mathrm{~S}_{2} \mathrm{O}_{3}$ & $\left(\mathrm{NH}_{4}\right)_{2} \mathrm{CO}_{3}$ & $\mathrm{NH}_{4} \mathrm{Cl}$ \\
\hline $\mathrm{O}$ & $12.64 \pm 0.14$ & $4.01 \pm 0.98$ & $15.32 \pm 0.13$ & $14.60 \pm 0.26$ \\
\hline $\mathrm{Al}$ & $1.07 \pm 0.01$ & $0.14 \pm 0.02$ & $0.81 \pm 0.01$ & $1.06 \pm 0.09$ \\
\hline $\mathrm{Si}$ & $0.64 \pm 0.04$ & $0.21 \pm 0.05$ & $0.37 \pm 0.04$ & $0.67 \pm 0.05$ \\
\hline $\mathrm{Fe}$ & $7.89 \pm 0.13$ & $1.67 \pm 0.04$ & $7.27 \pm 0.02$ & $11.15 \pm 0.62$ \\
\hline $\mathrm{Ni}$ & $0.41 \pm 0.11$ & - & $1.23 \pm 0.07$ & - \\
\hline $\mathrm{Cu}$ & $28.66 \pm 0.28$ & $73.63 \pm 1.93$ & $25.34 \pm 0.03$ & $9.21 \pm 0.47$ \\
\hline $\mathrm{Zn}$ & $9.47 \pm 0.22$ & - & $9.12 \pm 0.09$ & $6.25 \pm 0.32$ \\
\hline $\mathrm{Ag}$ & $20.06 \pm 0.01$ & $0.94 \pm 0.21$ & $22.37 \pm 0.25$ & $18.75 \pm 1.16$ \\
\hline $\mathrm{Sn}$ & $8.19 \pm 0.04$ & $0.58 \pm 0.05$ & $8.52 \pm 0.23$ & $11.93 \pm 0.68$ \\
\hline $\mathrm{Pb}$ & $10.27 \pm 0.04$ & $2.02 \pm 0.08$ & $7.60 \pm 0.04$ & $24.21 \pm 2.27$ \\
\hline$S$ & $0.74 \pm 0.02$ & $16.80 \pm 0.95$ & - & - \\
\hline $\mathrm{C}$ & - & & $2.08 \pm 0.01$ & - \\
\hline $\mathrm{Cl}$ & - & - & - & $2.18 \pm 0.04$ \\
\hline
\end{tabular}

(a)
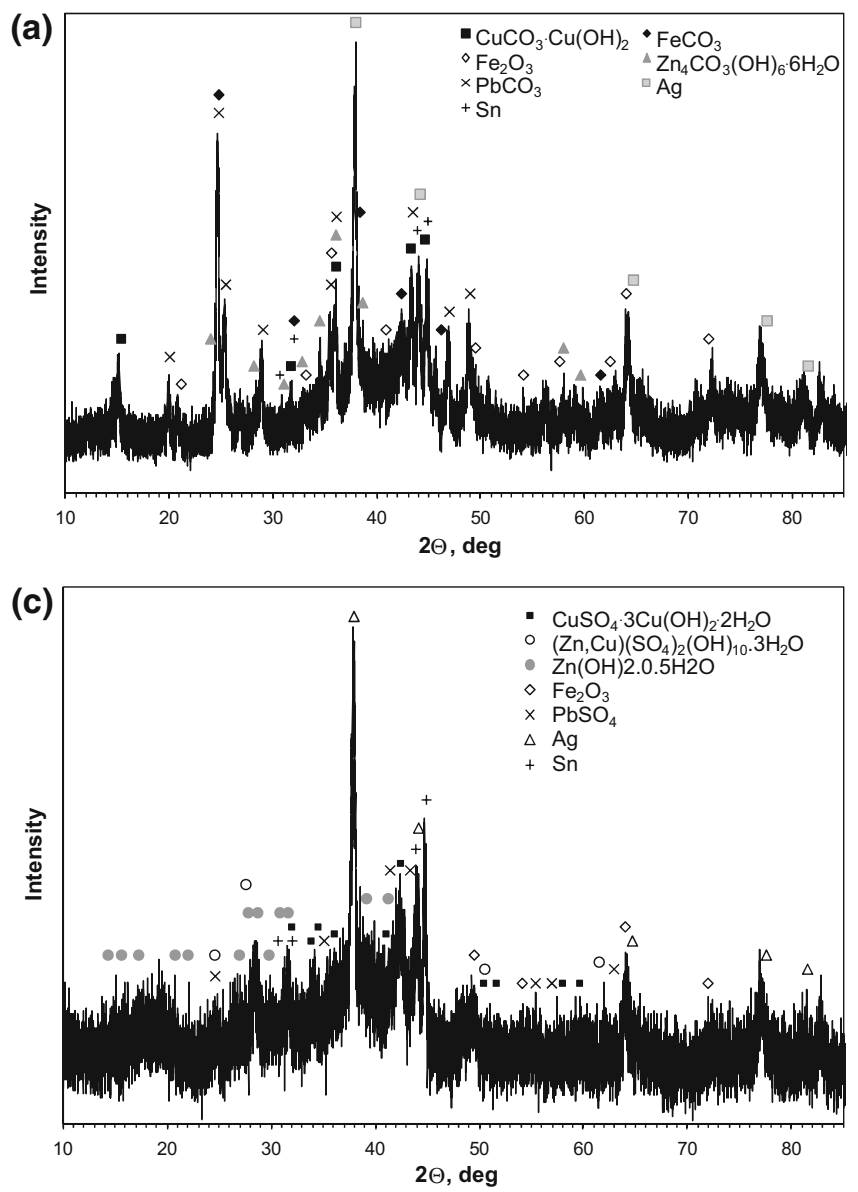
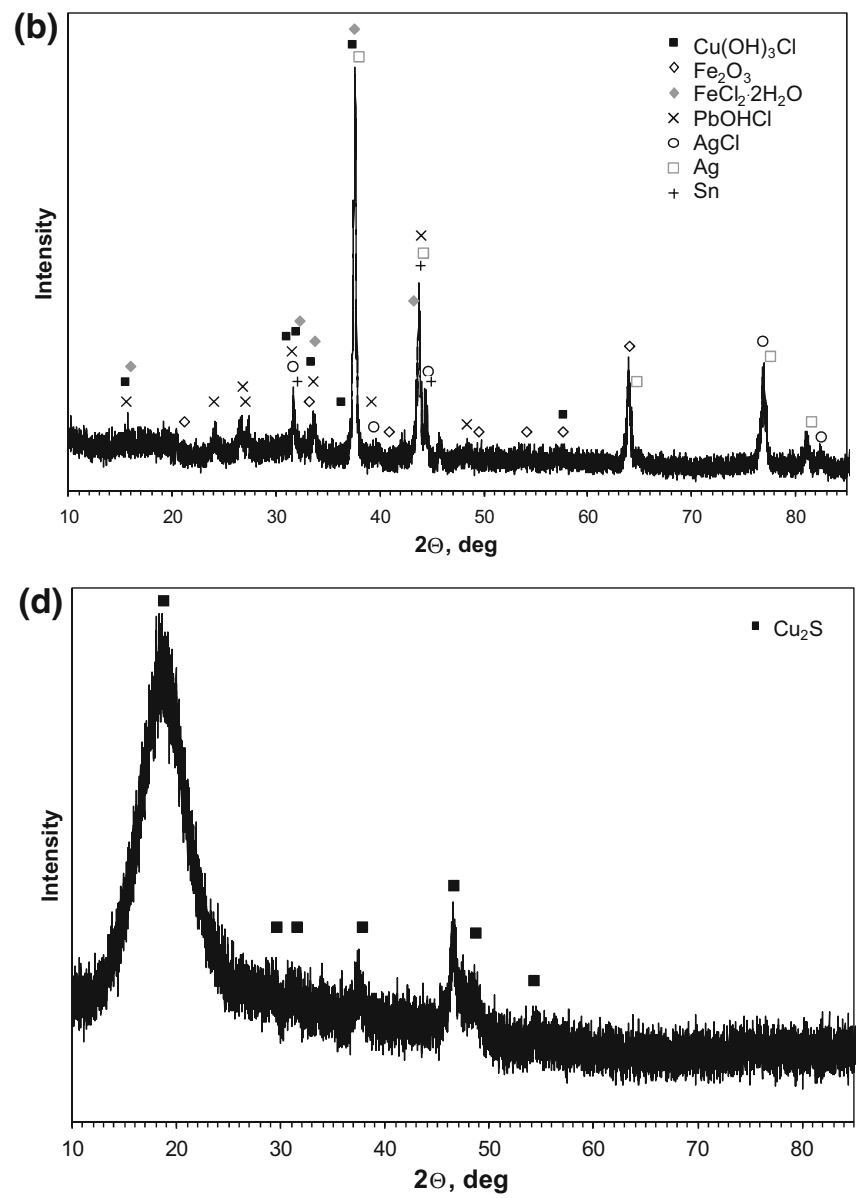

Fig. 7 Diffraction patterns of the slimes formed in the solutions: a carbonate, $\mathbf{b}$ chloride, $\mathbf{c}$ sulfate, and $\mathbf{d}$ thiosulfate 

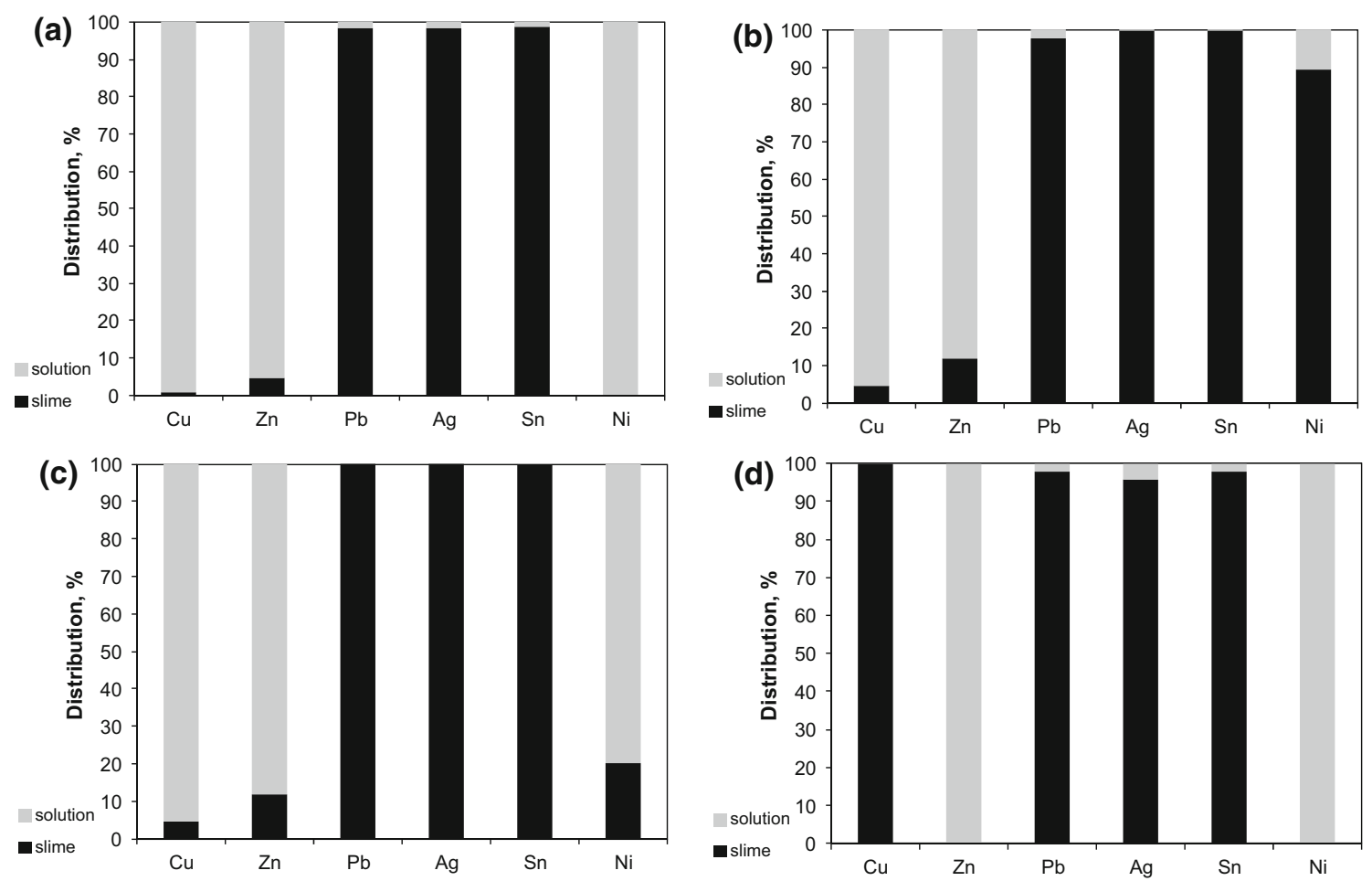

Fig. 8 Distribution of metals between solution and slime the ammoniacal baths: a chloride, $\mathbf{b}$ carbonate, $\mathbf{c}$ sulfate, and $\mathbf{d}$ thiosulfate

$$
\begin{aligned}
2 \mathrm{Cu}\left(\mathrm{NH}_{3}\right)_{4}^{2+}+2 \mathrm{~S}_{2} \mathrm{O}_{3}^{2-} \rightarrow & 2 \mathrm{Cu}\left(\mathrm{NH}_{3}\right)_{2}^{+}+4 \mathrm{NH}_{3} \\
+ & \mathrm{S}_{4} \mathrm{O}_{6}^{2-}
\end{aligned}
$$

as an intermediate stage of the process (6) followed by the reactions (8) and (9).

Zinc and nickel leaching from the alloy was similar in both chloride and carbonate solutions, but it was hindered in the sulfate system and totally inhibited in the thiosulfate bath. Behavior of lead in ammoniacal bath seemed quite surprised, since no dissolution of the metal was expected. In fact, up to $5 \mathrm{mg} / \mathrm{dm}^{3} \mathrm{~Pb}$ (II) was detected in the solutions, but a large scatter of the results with the time was found. Lim et al. [10] reported leaching of lead powder in ammonium-ammonium sulfate bath and after initial lead dissolution a decrease of $\mathrm{Pb}(\mathrm{II})$ ions concentration was observed in relatively short time period. Oishi et al. [16] stated that metallic lead can be easily oxidized by copper(II) ions to $\mathrm{Pb}$ (II) species in ammoniacal solutions. Authors found that increased ammonia concentration in ammonium chloride solutions was accompanied by enhanced lead solubility. Analogous tendency was mentioned for sulfate and nitrate solutions. This was attributed to the formation of lead ammine complexes, but these were not identified.

Other metals present in the investigated alloy were slowly dissolved from the material. Figure 5 shows final concentrations of silver, tin and iron found in the baths. Tin and iron seemed to be present in the slime particles flowing in the bulk solution, since both metals are not able to form stable ammonia complexes. The highest contents of the metals were observed in the chloride bath. It seems obvious, since chloride ions show the most aggressive action towards corrosion of metals and some amounts of slime flowing in the bulk solution were observed.

Figure 6 shows exemplary morphologies of the slimes produced during leaching. These were black and porous layers. Slimes obtained in the sulfate and carbonate systems were difficult to remove from the alloy surface due to close adjacency to the sample. A slightly different morphology had the slimes collected from the samples dissolved in thiosulfate (thin plates) and chloride (fine powder) baths and both could be easily separated from the alloy.

Composition of the slimes obtained in the leaching experiments is presented in Table 2, while Fig. 7 shows corresponding diffraction patterns. Copper, silver, lead, zinc, tin and iron were main metals in the slimes, but some amounts of other elements were also detected. The presence of oxygen, sulfur, carbon or chlorine shows formation of the salts characteristic for the type of the leaching solution, hence basic salts, mainly of copper and zinc, were found. The high levels of lead and tin confirm that they do not form stable complexes with ammonia and accumulate in the solid phase. XRD analysis shows that lead can spontaneously dissolve in ammoniacal baths, but then it was precipitated in the secondary reactions as carbonate, 

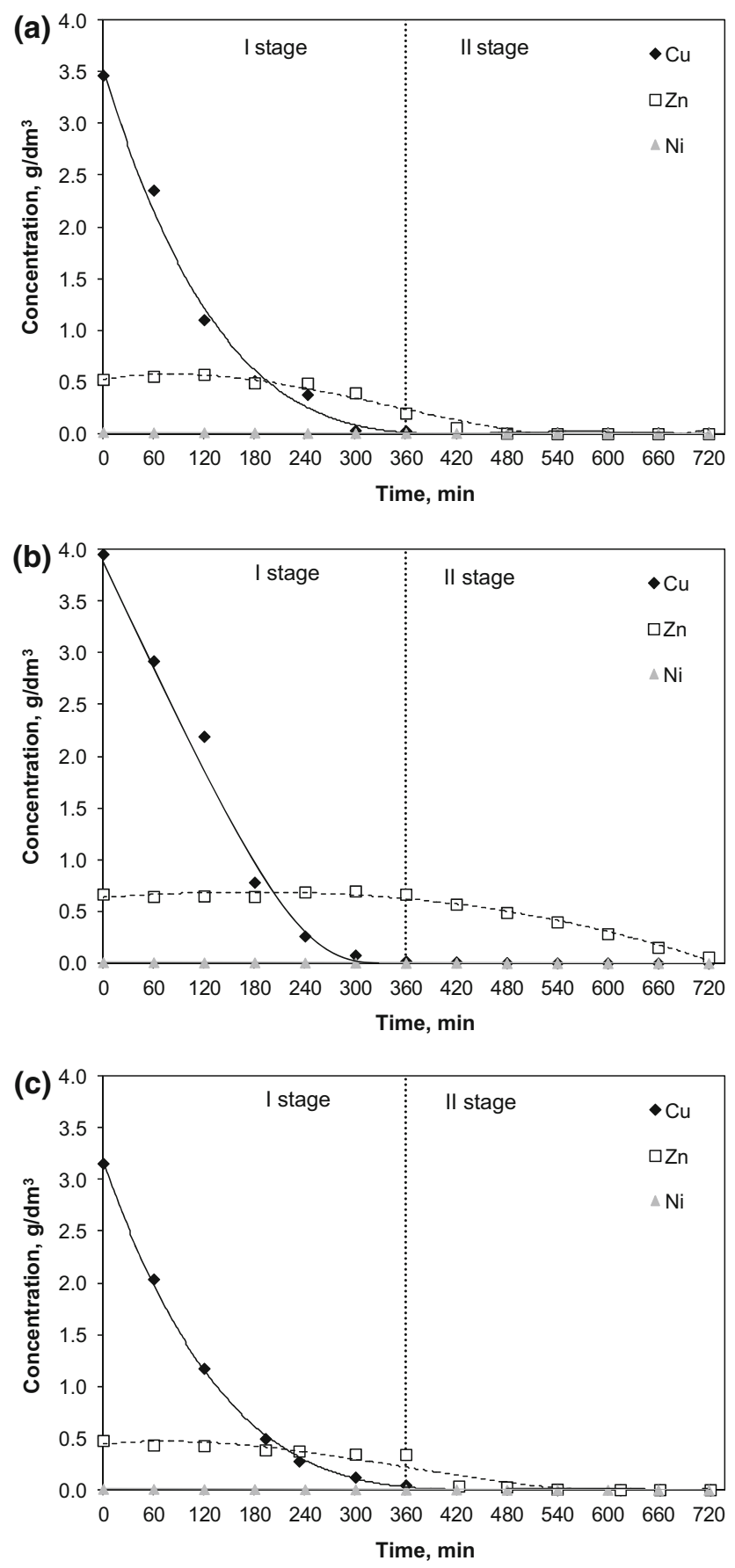

Fig. 9 Changes of metal ions concentration with electrolysis time in ammoniacal solutions: a chloride, $\mathbf{b}$ carbonate, and $\mathbf{c}$ sulfate

sulfate or basic chloride. No lead(II) chloride was found, but it is not surprised since solubility of $\mathrm{PbOHCl}$ in aqueous solution is much lower $\left(1.1 \mathrm{mg} / \mathrm{dm}^{3}\right)$ than $\mathrm{PbCl}_{2}$ $\left(9.9 \mathrm{~g} / \mathrm{dm}^{3}\right)$. Tin was not treated by the electrolytes, and metal was accumulated in the slimes. Increased silver contents suggest that phase III did not dissolve totally despite that soluble $\mathrm{Ag}\left(\mathrm{NH}_{3}\right)_{2}^{+}$complexes can be potentially generated. Actually, metallic silver was identified in

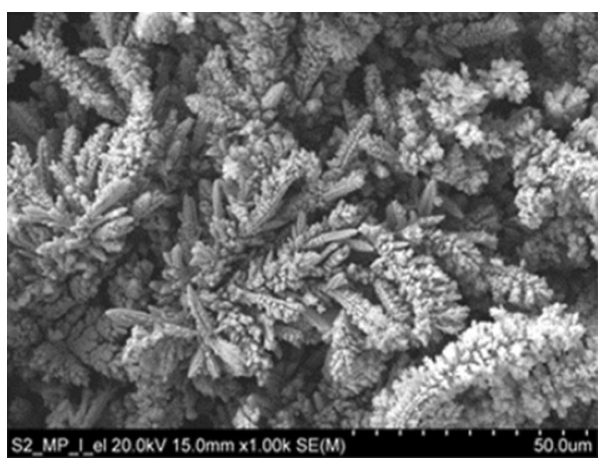

Fig. 10 Morphology of copper cathode obtained in carbonate solution (I stage)

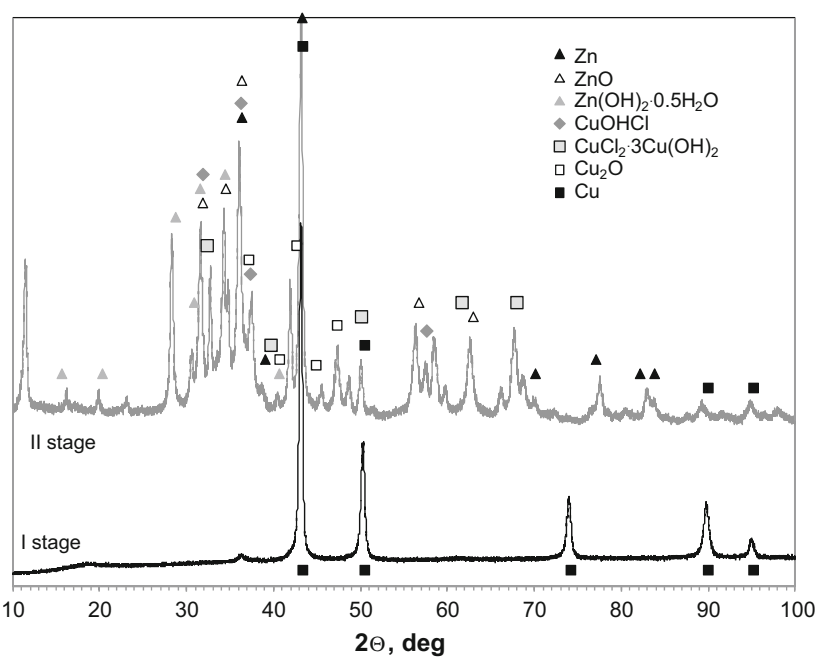

Fig. 11 Diffraction patterns of the cathodic deposits from chloride bath

the precipitates. Aggressive action of chloride bath resulted in the formation of $\mathrm{AgCl}$ in the slime and the highest silver ions concentration in the solution (Fig. 5). Dominating components of the slime from thiosulfate solution were copper and sulfur at the weight ratio of approximately 4 , which indicated the presence of $\mathrm{Cu}_{2} \mathrm{~S}$.

Figure 8 shows distribution of the main metals between the solutions and the slimes. In all cases, copper and zinc were transferred almost totally to the electrolyte, except copper in thiosulfate bath. Remaining metals, like tin, lead and silver accumulated in the slimes. It shows that quite good separation of metals during spontaneous dissolution of the multicomponent alloy in ammoniacal solutions can be obtained.

\section{Electrolysis stage}

Chloride, carbonate and sulfate solutions obtained in the previous stage were filtered to remove the slimes and diluted to $1 \mathrm{dm}^{3}$ and then portions of the electrolytes 
were used for selective copper recovery. Electrolysis was carried out in two 6-h-long steps. Figure 9 shows changes of metal ions during the process. It was found that in all cases, copper was totally removed from the bath in the first stage. Copper cathodes of $97-99.9 \%$ purity were obtained at the current efficiencies of approx. $40 \%$ in sulfate and chloride baths or $60 \%$ in the carbonate solution. In the second stage, deposition of zinc was carried out giving the cathodic deposits containing zinc (50-86\%) and copper as well as nickel traces, but it was accompanied by very low current efficiency (2-6\%). In all cases, porous deposits were produced (Fig. 10).

Figure 11 shows exemplary diffraction patterns of the deposits obtained in the chloride bath. Phase analysis confirmed that in the stage I of the electrolysis, metallic copper was deposited in all solutions. However, intensive hydrogen coevolution during the second stages favored precipitation of inorganic compounds at the cathode surface. Therefore,
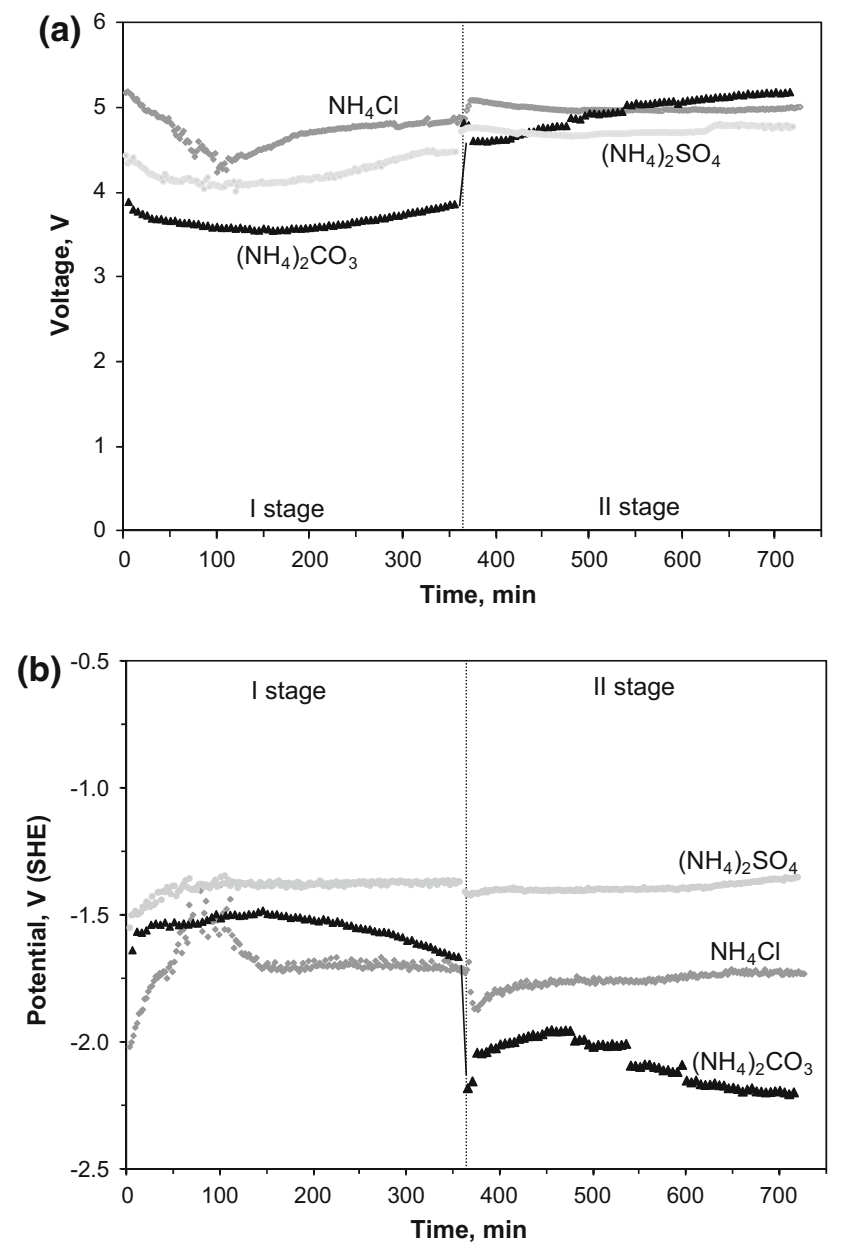

Fig. 12 Changes of a voltage and $\mathbf{b}$ cathode potential during electrolysis zinc layers contaminated mainly by salts (chloride, carbonate or sulfate) or oxides were obtained.

Despite similar metal ions concentrations, electrolysis voltage was maintained between $3.5 \mathrm{~V}$ for carbonate bath and approx. $4.9 \mathrm{~V}$ for chloride solution during I stage, while almost constant value of $4.8 \pm 0.1 \mathrm{~V}$ was stabilized when zinc recovery was realized (Fig. 12a). It corresponded to low cathode potential $(-1.4$ to $-2.2 \mathrm{~V})$ caused by the hydrogen evolution as dominating electrode reaction.

Energy consumption on the mass unit of the deposited metal for the copper electrowinning step was calculated. Above values of electrolysis voltages were assumed as average values, hence presented results are only qualitative. It was found that consumption energy was rather comparable in the chloride and sulfate systems (10 and $9 \mathrm{~kW} / \mathrm{t}$, respectively). The most profitable conditions were for carbonate system $(5 \mathrm{~kW} / \mathrm{t})$, where highest current efficiency of the electrolysis and low electrolysis voltage were observed.

\section{Conclusions}

Smelting of low-grade electric and electronic wastes results in a polymetallic and multiphase alloys. The high-copper alloy can dissolve spontaneously in ammoniacal solutions with added copper(II) ions. The leaching in chloride, carbonate and sulfate baths allowed a distinct metal separation with copper and zinc accumulating in the electrolyte, while metallic tin and silver remained in the slimes. Lead can be affected by the electrolytes, but it precipitates in secondary reactions as corresponding salts. Copper may be selectively recovered from the baths by the electrolysis, leaving zinc ions in the solution.

Ammonium-thiosulfate system is not applicable for leaching of the copper alloy due to secondary reactions of the formation of copper(I) thiosulfate complexes and precipitation of copper(I) sulfide thus inhibiting dissolution process.

Obtained result showed that the most favorable conditions for the alloy dissolution can be achieved in the ammonia-ammonium carbonate system. It allows leaching copper effectively, without uncontrolled alloy degradation (as in the chloride bath) and recovering the metal at the lowest electrolysis voltage $(3.5 \mathrm{~V})$, highest current efficiency $(60 \%)$ and high purity $(99.9 \% \mathrm{Cu})$.

Further research is going to be focused on the direct recovery of copper from the alloy by anodic dissolution of the material in ammoniacal solutions. It should enhance transfer of copper from the alloy to the electrolyte and 
cathode in one step, but behavior of other metals is currently uncertain.

Acknowledgments This research work was supported by The National Centre for Research and Development (Poland) under grant no. INNOTECH-2/IN2/18/181960/NCBR.

Open Access This article is distributed under the terms of the Creative Commons Attribution License which permits any use, distribution, and reproduction in any medium, provided the original author(s) and the source are credited.

\section{References}

1. Robinson BH (2009) E-waste: an assessment of global production and environmental impacts. Sci Total Environ 408:183-191

2. Ongondo FO, Williams ID, Cherrett TJ (2011) How are WEEE doing? A global review of the management of electrical and electronic wastes. Waste Manag 30:714-730

3. Li J, Lopez BN, Liu L, Zhao N, Yu K, Zheng K (2013) Regional or global WEEE recycling. Where to go? Waste Manag 33:923-934

4. Cui J, Zhang L (2008) Metallurgical recovery of metals from electronic waste: a review. J Haz Mater 158:228-256

5. Tuncuk A, Stazi V, Akcil A, Yazici EY, Deveci H (2012) Aqueous metal recovery techniques from e-scrap: hydrometallurgy in recycling. Min Eng 25:28-37

6. Pant D, Joshi D, Upreti MK, Kotnala RK (2012) Chemical and biological extraction of metals present in $\mathrm{E}$ waste: a hybrid technology. Waste Manag 32:979-990
7. Birloaga I, Michelis ID, Ferella F, Buzatu M, Veglió F (2013) Study on the influence of various factors in the hydrometallurgical processing of waste printed circuit boards for copper and gold recovery. Waste Manag 33:935-941

8. Oishi T, Koyama K, Alam S, Tanaka M, Lee J-C (2007) Recovery of high purity copper cathode from printed circuit boards using ammoniacal sulfate or chloride solutions. Hydrometallurgy 89:82-88

9. Bari F, Begum N, Hamaludin SB, Hussin K (2009) Selective leaching for the recovery of copper from $\mathrm{PCB}$, proceedings of the Malaysian Metallurgical Conference '09, 1-1.12 2009, Kuala Perlis, pp 1-4

10. Lim Y, Kwon O-K, Lee J, Yoo K (2013) The ammonia leaching of alloy produced from waste printed circuit boards smelting process. Geosys Eng 16:216-224

11. Burzyńska L, Gumowska W, Rudnik E (2004) Influence of the composition of $\mathrm{Cu}-\mathrm{Co}-\mathrm{Fe}$ alloys on their dissolution in ammoniacal solutions. Hydrometallurgy 71(3-4):447-455

12. Osseo-Asare K (1981) Application of activity-activity diagrams to ammonia hydrometallurgy: $\mathrm{Fe}-\mathrm{NH}_{3}-\mathrm{H}_{2} \mathrm{O}-\mathrm{CO}_{3}$ and $\mathrm{Fe}-\mathrm{NH}_{3}-$ $\mathrm{H}_{2} \mathrm{O}-\mathrm{SO}_{4}$ systems at $25^{\circ} \mathrm{C}$. Trans Inst Min Met C 90:159-163

13. Das RP, Anand S (1995) Precipitation of iron oxides from ammonia-ammonium sulphate solutions. Hydrometallurgy 38:161-173

14. Aylmore MG, Muir DM (2001) Thiosulfate leaching of gold-a review. Min Eng 14(2):135-174

15. Breuer PL, Jeffrey MI (2003) Copper catalysed oxidation of thiosulfate by oxygen in gold leach solutions. Min Eng 16:21-30

16. Oishi T, Yaguchi M, Koyama K, Tanaka M, Lee J-C (2008) Effect of phosphate on lead removal during a copper recycling process from wastes using ammoniacal chloride solution. Hydrometallurgy 90:161-167 